\title{
HELICOBACTER PYLORI
}

\section{Relationship between Helicobacter pylori babA2 status with gastric epithelial cell turnover and premalignant gastric lesions}

\author{
J Yu, W K Leung, M Y Y Go, M C W Chan, K F To, E K W Ng, F K L Chan, T K W Ling, \\ S C S Chung, J J Y Sung
}

Background: Helicobacter pylori blood group antigen binding adhesin (BabA) mediates bacterial adherence to human blood group antigens on gastric epithelium. Although strains harbouring babA2 were recently found to be associated with peptic ulcer and gastric cancer, the role of babA2 in cellular turnover, severity of gastritis, and premalignant changes is poorly understood.

Aim: We correlated $H$ pylori babA2, vacuolating toxin (vacA), and cytotoxin associated gene $A$ $(\operatorname{cag} A)$ genotypes with the severity of gastric inflammation and epithelial cell turnover in a group of Chinese patients from an area with a high incidence of gastric cancer.

Patients and methods: $H$ pylori isolates were obtained from 104 Chinese patients who participated in a gastric cancer prevention programme. Genotype variants of babA2, vacA, and $\operatorname{cag} A$ were determined by polymerase chain reaction. Antrum and corpus histopathology was examined according to the updated Sydney classification. Apoptosis was scored by terminal uridine deoxynucleotidyl nick end labeling (TUNEL) and proliferation by Ki-67 immunostaining.

See end of article for authors' affiliations

Correspondence to: Dr J J Y Sung, Department of Medicine and Therapeutics, Prince of Wales Hospital, Shatin NT, Hong Kong; email: joesung@cuhk.edu.hk

Accepted for publication 30 May 2002
Results: Of the 104 patients, $102(98.1 \%)$ harboured cagA $A^{+}$strains and all had vacA s1 genotype. The babA2 $2^{+}$strains were found in $83(79.8 \%)$ patients and were associated with higher lymphocytic infiltration $(p=0.028)$, presence of glandular atrophy (odds ratio (OR) $7.5,95 \%$ confidence interval (Cl) 2.3-24.3), and intestinal metaplasia (OR 7.4,95\% Cl 2.2-25.3) in the antrum. Increased epithelial proliferation was also noted in individuals infected with babA2 $2^{+}$strains $(p=0.025)$. Strains harbouring $\operatorname{cag} A^{+} / v a c A s l$ genotypes lacked this association in the absence of babA2.

Conclusions: The presence of babA2+ $\mathrm{H}$ pylori strains alone or in combination with $\operatorname{cag} A^{+}$and $\operatorname{vac} A$ s1 was associated with the presence of preneoplastic gastric lesions.
$H$ icobacter pylori colonises the human stomach and is the principal cause of chronic gastritis, peptic ulcer disease, gastric atrophy (AT), intestinal metaplasia (IM), and gastric adenocarcinoma. However, $H$ pylori infection is usually asymptomatic and only a minority of patients develops serious clinical outcomes. The reasons for this may be related to differences in genetic susceptibility of the host, ${ }^{1}$ environmental factors, ${ }^{2-4}$ and genetic diversity of $H$ pylori. ${ }^{5}{ }^{6}$ In this context, the relevance of specific $H$ pylori virulence associated genes has been extensively studied. The cytotoxin associated gene A $(\operatorname{cag} A)$ was the first to be identified and was shown to be associated with duodenal ulcers and gastric carcinoma. ${ }^{78}$ The vacuolating toxin (VacA) was subsequently discovered. Allelic variants of the vacA gene were identified in the signal region $(\mathrm{s} 1, \mathrm{~s} 2)$ and mid region $(\mathrm{ml}, \mathrm{m} 2)$ of the gene which appear to regulate cytotoxic activity. ${ }^{9}$ Specifically, vacA sl/ml strains have higher cytotoxic activity than $\mathrm{sl} / \mathrm{m} 2$ strains whereas s $2 / \mathrm{m} 2$ strains have no cytotoxic activity. ${ }^{9}$

Apart from bacterial toxins, recent studies have provided evidence that bacterial adherence factors may also contribute to the pathogenicity of $\mathrm{H}$ pylori. The blood group antigen binding adhesin (BabA) has been shown to mediate adherence of $H$ pylori to human blood group antigens on gastric epithelial cells. $^{1011}$ Two corresponding genes encoding BabA have been cloned: $b a b A 1$ and $b a b A 2$, but only the $b a b A 2$ gene is functionally active. ${ }^{12}$ Recently, $b a b A 2$ was found to be significantly associated with duodenal ulcer and gastric cancer. ${ }^{13}$ None the less, the importance of $H$ pylori adherence factors to gastric epithelial cell turnover, degree of gastric inflammation, glandular AT, and IM is poorly understood. It is further complicated by the observations that the frequency of these virulence determinants and their association with gastrointestinal pathologies appears to vary considerably between different geographic regions. In the present study, we correlated $b a b A 2, c a g A$, and vacA genotypes with gastric inflammation, presence of glandular atrophy and IM, and gastric epithelial cell turnover in Chinese patients.

\section{MATERIALS AND METHODS}

\section{Study design and subjects}

This was a cross sectional study that examined the correlation between various $H$ pylori genotypes, gastric inflammation, and cellular turnover. Subjects were previously recruited in a randomised control trial of $H$ pylori eradication in the prevention of gastric cancer in Yantai County, Shandong province of China, where the incidence of gastric caner is among the highest in China. ${ }^{14}$ Endoscopy was performed in all subjects, with gastric biopsies obtained. Two antral and two corpus biopsies were fixed in 10\% buffered formalin and processed for histological examination. One extra antral biopsy was used for bacterial culture for $H$ pylori.

In this study, $104 \mathrm{H}$ pylori positive subjects (median age 50 years; range 39-75) were studied. These patients were randomly selected from those with persistent active $H$ pylori infection at first follow up, as detected by bacterial culture. ${ }^{15}$ None of these patients had previously received anti-Helicobacter therapy.

\section{$H$ pylori culture}

One antral biopsy was placed in selective transport medium and cultured on horse blood agar at $37^{\circ} \mathrm{C}$ under micro-

Abbreviations: $I M$, intestinal metaplasia; $\operatorname{cag} A$, cytotoxin associated gene $A$; VacA, vacuolating toxin; $A T$, atrophy; $T d T$, terminal deoxynucleotidyl transferase; TUNEL, triphosphate nick end labeling; $\mathrm{Al}$, apoptosis index; Pl, proliferation index; OR, odds ratio; BabA, blood group antigen binding adhesin; PCR, polymerase chain reaction. 
Table1 Primer sequences for polymerase chain reaction based genotyping of Helicobacter pylori isolates

\begin{tabular}{|c|c|c|c|}
\hline Ref & Gene & Sequence $\left(5^{\prime}\right.$ to $\left.3^{\prime}\right)$ & Product size \\
\hline \multirow[t]{3}{*}{13} & $\operatorname{vac} A \mathrm{sl} / \mathrm{s} 2$ & & \\
\hline & Forward & ATGGAAATACAACAAACACAC & $259 \mathrm{bp}(\mathrm{s} 1)$ \\
\hline & $\begin{array}{c}\text { Reverse } \\
\operatorname{vac} A \mathrm{~m} 1 / \mathrm{m} 2\end{array}$ & CTGCTTGAATGCGCCAAAC & $286 \mathrm{bp}(\mathrm{s} 2)$ \\
\hline \multirow{2}{*}{17} & Forward & CAATCTGTCCAATCAAGCGAG & $570 \mathrm{bp}(\mathrm{m} 1)$ \\
\hline & Reverse & GCGTCTAAATAATTCCAAGG & $645 \mathrm{bp}(\mathrm{m} 2)$ \\
\hline \multirow[t]{3}{*}{13} & $\operatorname{cag} A$ & & \\
\hline & Forward & ATAATGCTAAATTAGACAACTTGAGCGA & $297 \mathrm{bp}$ \\
\hline & $\begin{array}{l}\text { Reverse } \\
\text { babA2 }\end{array}$ & TTAGAATAATCAACAAACATCACGCCAT & \\
\hline \multirow{2}{*}{16} & Forward & AATCCAAAAAGGAGAAAAAGTATGAAA & $850 \mathrm{bp}$ \\
\hline & Reverse & TGTTAGTGATTTCGGTGTAGGACA & \\
\hline
\end{tabular}

aerophilic conditions, as previously described.$^{15} \mathrm{H}$ pylori was identified by typical colony morphology, Gram stain, and positive biochemical testing for urease, catalase, and oxidase. Bacteria were harvested from the plates using sterile cotton swabs and stored at $-70^{\circ} \mathrm{C}$ in brucella broth plus $30 \%$ (vol/vol) fetal calf serum and $20 \%$ ( vol $/ \mathrm{vol}$ ) glycerol. All frozen isolates were controlled for contamination.

\section{Detection of $\boldsymbol{H}$ pylori genotypes and sequencing}

$H$ pylori cagA, vacA, and babA2 genotypes were determined by polymerase chain reaction (PCR). Genomic DNA was extracted from H pylori using the High Pure PCR Template Preparation Kit (Roche, Germany). The integrity of the DNA was assessed by $1.2 \%$ agarose gels stained with ethidium bromide. PCR reactions were performed in a total volume of $50 \mu \mathrm{l}$ which contained 50 pmol of primers, $100 \mathrm{ng}$ of genomic DNA, $1.0 \mathrm{mM}$ of each of the four dNTPs, and 2 units of AmpliTaq DNA polymerase (PerkinElmer, Norwalk, Connecticut, USA). Primer sequences were described previously ${ }^{13}{ }^{16}{ }^{17}$ and are listed in table 1 for reference. The amplified PCR products were resolved in $1.5 \%$ agarose gels, stained with ethidium bromide, and visualised under a short wavelength ultraviolet light source. The sequences of the PCR products were confirmed by automated sequencing (ABI Prism 310 Genetic Analyzer; Perkin Elmer, Branchburg, New Jersey, USA) using the same primer pairs.

\section{Histological assessment}

Haematoxylin-eosin stained sections of the gastric antrum and corpus biopsies were examined by a single pathologist (KFT) who was blinded to the other experimental results. Slides were coded and evaluated histologically for the following parameters: (1) activity of gastritis (granulocytic cell infiltration); (2) chronicity of gastritis (lymphocytic and plasma cells infiltration); (3) glandular AT; and (4) IM. Each parameter was graded

Table 2 Distribution of different Helicobacter pylori genotypes in 104 patients

\begin{tabular}{|c|c|}
\hline Genotype & No (\%) \\
\hline babA2 $2^{+}$ & 83 (79.8) \\
\hline $\operatorname{cag} A^{+}$ & $102(98.1)$ \\
\hline \multicolumn{2}{|l|}{$\operatorname{vac} A$} \\
\hline s1 & $104(100)$ \\
\hline s2 & $0(0)$ \\
\hline $\mathrm{ml}$ * & 43 (41.3) \\
\hline $\mathrm{m} 2 *$ & $58(55.8)$ \\
\hline $\operatorname{cagA}^{+} / \operatorname{vac} A$ sl & 102 (98) \\
\hline $\operatorname{cag} A^{+} / \operatorname{vac} A$ m 1 & 43 (41.3) \\
\hline $\mathrm{babA2}^{+} / \mathrm{cagA}^{+} / \operatorname{vac} A$ sl & $82(78.8)$ \\
\hline babA2 $/ \operatorname{cag} A^{+} / \operatorname{vac} A$ sl & 20 (19.2) \\
\hline
\end{tabular}

*There were three strains that could not be typed. as none (0), mild (1), moderate (2), or severe (3) according to the updated Sydney classification. ${ }^{18}$ Glandular atrophy was defined as loss of gastric glands with replacement by metaplastic epithelium or fibrosis. IM was defined as the presence of foci where at least three neighbouring gastric pits contained two or more goblet cells in each pit.

\section{Assessment of apoptosis and determination of apoptosis index}

Apoptosis was determined by the terminal deoxynucleotidyl transferase (TdT) mediated deoxyuridine triphosphate nick end labeling (TUNEL) technique (ApopTag; Intergen, New York, USA), as described previously. ${ }^{19}$ In addition, positively stained cells should also bear morphological characteristics of apoptosis, including chromatin condensation, nuclear disintegration, and formation of crescentic caps of condensed chromatin at the nuclear periphery. The apoptosis index (AI) was calculated as the ratio of TUNEL positive nuclei over the total number of cells counted (usually more than 1000).

\section{Assessment of proliferation and determination of proliferation index}

Proliferation was assayed by immunoperoxidase staining for Ki-67, a proliferation associated antigen that has been used extensively in the assessment of proliferation in the stomach. $^{19}$ In brief, paraffin embedded sections were dewaxed, dehydrated, and then subjected to microwave antigen retrieval. Endogenous peroxidase was blocked by 3\% hydrogen peroxide. Normal rabbit serum $(5 \%)$ was applied to prevent non-specific binding of primary monoclonal antibodies. The tissue was incubated with monoclonal mouse antihuman Ki-67 antibody (Clone: mib 1, isotype: IgG1, without dilution; Zymed, San Francisco, California, USA). Biotinylated rabbit antimouse antibody (dilution 1:200; Dako, Glostrup, Denmark) was applied as secondary antibody and followed by application of avidin-biotinylated peroxidase complex (dilution 1:100; Dako). The slides were developed in 3,3diaminobenzidine tetrahydrochloride (DAB, Dako) and counterstained with Mayer haematoxylin. The proliferation index (PI) was expressed as a percentage of the ratio of Ki-67 positive nuclei to the total nuclei counted. ${ }^{19}$

\section{Statistical analysis}

Statistical analysis was performed using the Statistical Package for the Social Science program (SPSS, version 10.0) and MINITAB (Release 7.2, Minitab, Inc). As gastric histology, particularly AT and IM, may be confounded by the effect of age, we have adjusted for the effect of age in this study. Mantel-Haenszel statistics were used to assess the relationship between individual genotypes and the presence of activity, chronicity, glandular AT, and IM after adjusting for the effect of age; the results are expressed as common odds ratios (OR) with the corresponding 95\% confidence intervals (CI). 


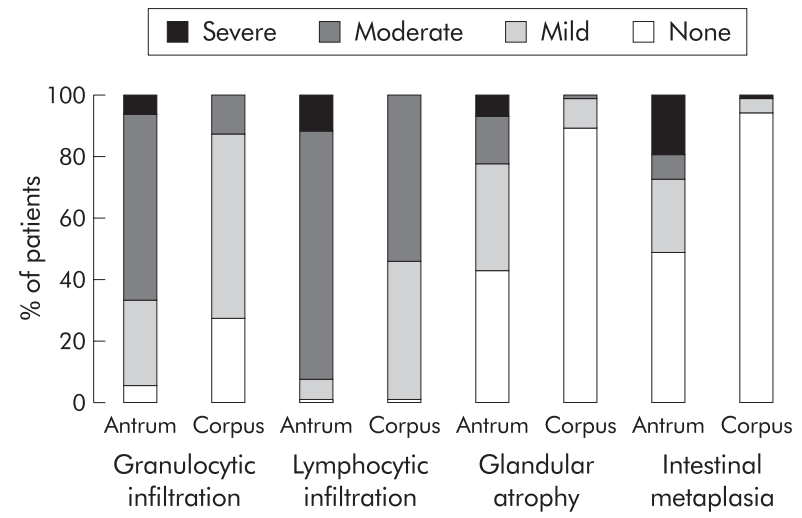

Figure 1 Distribution of the severity of gastritis in all study patients $(n=104)$. The degree of granulocytic infiltration (activity), lymphocytic infiltration (chronicity), glandular atrophy, and intestinal metaplasia was graded as none (0), mild (1), moderate (2), or severe (3), as suggested by the updated Sydney classification. ${ }^{18}$

The age of the subjects was stratified into two groups ( $>50$ or $\leqslant 50$ years old) according to the median age of the study population. The Mann-Whitney U test was used to compare the severity of gastritis among different genotypes. Spearman's correlation coefficient was used to assess the correlation between (1) proliferation and severity of inflammation; and (2) age and AT/IM scores. The Pearson correlation coefficient was used to examine the correlation between epithelial cell proliferation and apoptosis. The two tailed independent $t$ test was performed to examine the difference in AI and PI among various genotypes. A two sided $p$ value of less than 0.05 was considered statistically significant.

\section{RESULTS}

\section{Characteristics of $\boldsymbol{H}$ pylori isolates}

Of the $104 \mathrm{H}$ pylori infected subjects, 102 (98.1\%) harboured $\mathrm{cagA}^{+}$strains. All $\mathrm{H}$ pylori isolates belonged to the vacA s s genotype and thus $98.1 \%$ were $c a g A^{+} / v a c A$ sl. For the middle $(\mathrm{m})$ region of the vacA gene, 101 isolates could be typed and the remaining three strains could not. There were $43(42.6 \%) \mathrm{ml}$ and $58(57.4 \%) \mathrm{m} 2$ strains. Eighty three $(79.8 \%)$ were $b a b A 2^{+}$ strains and the simultaneous presence of $\operatorname{cag} A, v a c A$ sl, and babA2 genes (triple positive) was found in $82(78.8 \%) \mathrm{H}$ pylori isolates (table 2). The presence of the babA2 genotype did not correlate with the presence of cagA or various vacA genotypes.

\section{Histological assessment of gastritis}

Most $H$ pylori infected patients had evidence of granulocytic and lymphocytic infiltration in the stomach (fig 1). Granulocytic infiltration was seen in $94.2 \%$ of antral biopsies and $72.1 \%$ of corpus biopsies. All except one $H$ pylori positive patient had lymphocytic infiltration. In general, the severity of inflammation was more marked in the antrum than in the body. Fifty three patients had IM and/or AT in the antrum whereas 12 patients had IM and/or AT in the body. The severity of glandular atrophy in the corpus, but not in the antrum, correlated with the age of the patient (antrum $r=0.09, \mathrm{p}=0.35$; corpus $r=0.24, \mathrm{p}=0.014)$. On the other hand, there was no significant correlation between IM and patient age (antrum $r=0.09, \mathrm{p}=0.39$; corpus $r=0.18, \mathrm{p}=0.08$ ).

\section{Correlation between $\boldsymbol{H}$ pylori genotypes and inflammation}

As most $H$ pylori infected patients had evidence of acute and chronic inflammatory infiltrates in the stomach, there was no significant correlation between different $H$ pylori genotypes and the presence of granulocytic and lymphocytic infiltrates in the antrum or body of the stomach $(\mathrm{p}>0.3)$. However, the presence of the $b a b A 2^{+}$genotype was associated with a higher degree of lymphocytic infiltration (chronicity) in the antrum $(\mathrm{p}=0.028$, table 3$)$.

\section{Correlation between $\boldsymbol{H}$ pylori genotypes and atrophy/metaplasia}

After adjustment for age, carriage of $b a b A 2^{+} H$ pylori isolates was associated with a higher frequency of glandular AT (OR 7.5, 95\% CI 2.3-24.3) and IM (OR 7.4, 95\% CI 2.2-25.3) in the antrum (table 4). A similar association was also demonstrated in triple positive $\left(\mathrm{babA2}^{+} / \mathrm{cagA}^{+} / \mathrm{vacA}\right.$ sl) $\mathrm{H}$ pylori isolates. The corresponding OR values for AT and IM in triple positive strains were 7.1 (95\% CI 2.2-23.3) and 7.0 (95\% CI 2.1-24.1). None of the $H$ pylori genotype or genotype combinations appeared to correlate with preneoplastic lesions in the corpus.

\section{Epithelial cell proliferation and apoptosis}

The association between cellular proliferation and apoptosis was examined. There was a significant correlation between PI and $\mathrm{AI}(r=0.37, \mathrm{p}=0.001)$ but there was no direct correlation between proliferation and severity of inflammation (both activity and chronicity).

\section{babA2 genotypes and cell proliferation}

Proliferation indexes of different genotypes are shown in fig 2. PI was significantly higher in $b a b A 2^{+}$isolates (mean (SD) 21.3 (17.7)) than in $b a b A 2^{-}$isolates (12.2 (13.9); mean difference 9.1, 95\% CI 1.46-16.70; $\mathrm{p}=0.025)$. In addition, there was a significant difference in PI between the $b a b A 2^{+} / \mathrm{cagA}^{+} / \mathrm{vacA} \mathrm{sl}^{+}$ (21.4 (17.9)) and $\mathrm{babA2}^{-} / \mathrm{cagA}^{+} / \mathrm{vacA} \mathrm{sl}^{+}(12.9$ (13.9)) isolates (mean difference 8.5, 95\% CI 0.64-16.29; $\mathrm{p}=0.041$ ). There was however no difference in proliferation between vacA ml (21.6 (18.6) ) and vacA $\mathrm{m} 2$ (16.5 (15.6)) strains (mean difference 5.1, $95 \% \mathrm{CI}-2.73-12.95 ; \mathrm{p}=0.19)$.

\section{baba2 genotypes and apoptosis}

Cellular apoptotic indexes of different $H$ pylori genotypes are demonstrated in fig 3. In contrast with proliferation, there was no difference in AI between $b a b A 2^{+}$and $b a b A 2^{-}$isolates (mean (SD) 0.67 (0.61) v 0.66 (0.52); mean difference 0.01 , 95\% CI $-0.27-0.29 ; \mathrm{p}=0.96)$. In addition, AI was comparable between

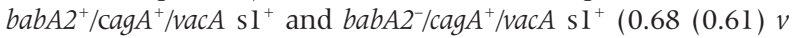
0.67 (0.53); mean difference $0.00,95 \%$ CI $-0.28-0.29$; $\mathrm{p}=0.98$ ),

Table 3 Helicobacter pylori genotypes and median (range) gastritis score

\begin{tabular}{|c|c|c|c|c|c|c|c|c|c|}
\hline & $\begin{array}{l}\text { babA2+ } \\
(n=83)\end{array}$ & $\begin{array}{l}\text { babA2- } \\
(n=21)\end{array}$ & $p$ Value & $\begin{array}{l}\operatorname{vac} A m 1 \\
(n=43)\end{array}$ & $\begin{array}{l}\operatorname{vacA} m 2 \\
(n=58)\end{array}$ & $\mathrm{p}$ Value & $\begin{array}{l}\operatorname{babA2}^{+} / \mathrm{cagA}^{+} / \\
\operatorname{vac} A \text { sl }(\mathrm{n}=82)\end{array}$ & $\begin{array}{l}\mathrm{babA2} / \mathrm{cag}^{+} / \\
\operatorname{vac} A \text { sl }(\mathrm{n}=20)\end{array}$ & $p$ Value \\
\hline \multicolumn{10}{|l|}{ Antrum } \\
\hline Activity & $2.00(0-3)$ & $2.00(0-3)$ & 0.49 & $2.00(0-3)$ & $2.00(0-3)$ & 0.12 & $2.00(0-3)$ & $2.00(0-3)$ & 0.59 \\
\hline Chronicity & $2.00(1-3)$ & $2.00(0-3)$ & 0.028 & $2.00(1-3)$ & $2.00(0-3)$ & 0.34 & $2.00(1-3)$ & $2.00(0-3)$ & 0.065 \\
\hline \multicolumn{10}{|l|}{ Corpus } \\
\hline Activity & $1.00(0-2)$ & $1.00(0-2)$ & 0.73 & $1.00(0-2)$ & $1.00(0-2)$ & 0.77 & $1.00(0-2)$ & $1.00(0-2)$ & 0.77 \\
\hline Chronicity & $2.00(1-2)$ & $2.00(0-2)$ & 0.82 & $1.00(1-2)$ & $2.00(0-2)$ & 0.59 & $2.00(1-2)$ & $2.00(0-2)$ & 0.99 \\
\hline
\end{tabular}

Comparison between different groups was made using the Mann-Whitney $U$ test.

Activity=degree of granulocytic cell infiltration; chronicity=degree of lymphocytic and plasma cell infiltration 
Table 4 Odds ratio of glandular atrophy (AT) and intestinal metaplasia (IM) in different Helicobacter pylori genotype combinations after adjustment for age

\begin{tabular}{|c|c|c|c|c|c|c|}
\hline & AT (\%) & Non-AT (\%) & Odds ratio* $(95 \% \mathrm{Cl})$ & IM (\%) & Non-IM (\%) & Odds ratio* $(95 \% \mathrm{Cl})$ \\
\hline \multicolumn{7}{|l|}{ Antrum } \\
\hline babA2+ & $54(65.1)$ & 29 (34.9) & & $49(59.0)$ & $34(41.0)$ & \\
\hline babA2 & $5(23.8)$ & $16(76.2)$ & $7.5(2.3-24.3)$ & $4(19.0)$ & 17 (81.0) & $7.4(2.2-25.3)$ \\
\hline $\operatorname{vac} A \mathrm{~m} l$ & $25(58.1)$ & 18 (41.9) & & $22(51.2)$ & $21(48.8)$ & \\
\hline $\operatorname{vac} A \mathrm{~m} 2$ & $32(55.2)$ & $26(44.8)$ & $1.1(0.5-2.4)$ & $30(51.7)$ & $28(48.3)$ & $0.9(0.4-2.1)$ \\
\hline $\mathrm{babA2}^{+} / \mathrm{cagA}^{+} / \mathrm{vacA} \mathrm{s} 1$ & $54(65.9)$ & $28(34.1)$ & & $49(59.8)$ & $33(40.2)$ & \\
\hline babA2 $/ \operatorname{cagA}^{+} / v a c A$ sl & $5(25.0)$ & $15(75.0)$ & $7.1(2.2-23.3)$ & $4(20.0)$ & $16(80.0)$ & $7.0(2.1-24.1)$ \\
\hline \multicolumn{7}{|l|}{ Corpus } \\
\hline babA2 $2^{+}$ & $8(9.6)$ & 75 (90.4) & & $5(6.0)$ & 78 (94.0) & \\
\hline babA2- & $3(14.3)$ & 18 (85.7) & $0.8(0.2-3.3)$ & $1(4.8)$ & $20(95.2)$ & $1.5(0.2-14.2)$ \\
\hline $\operatorname{vac} A \mathrm{ml}$ & $5(11.6)$ & $38(88.4)$ & & $2(4.7)$ & 41 (95.3) & \\
\hline $\operatorname{vac} A \mathrm{~m} 2$ & $6(10.3)$ & $52(89.7)$ & $1.0(0.3-3.6)$ & $4(6.9)$ & $54(93.1)$ & $0.6(0.1-3.3)$ \\
\hline $\mathrm{babA2}^{+} / \mathrm{cagA}^{+} / \operatorname{vacA}_{\mathrm{s} l}$ & $8(9.8)$ & $74(90.2)$ & & $5(6.1)$ & 77 (93.9) & \\
\hline babA2 $/ \operatorname{cagA}^{+} / v a c A$ sl & $3(15.0)$ & $17(85.0)$ & $0.7(0.2-3.1)$ & $1(5.0)$ & $19(95.0)$ & $1.4(0.2-13.2)$ \\
\hline
\end{tabular}

*Common odds ratio was given after adjustment for the effect of age ( $>50$ or $\leqslant 50$ years) by the Mantel-Haenszel statistics. $95 \% \mathrm{Cl}, 95 \%$ confidence interval.

As all strains were of the vacA s 1 genotype and $98.1 \%$ strains were cag $A^{+}$, analysis was not possible for these two genotypes.

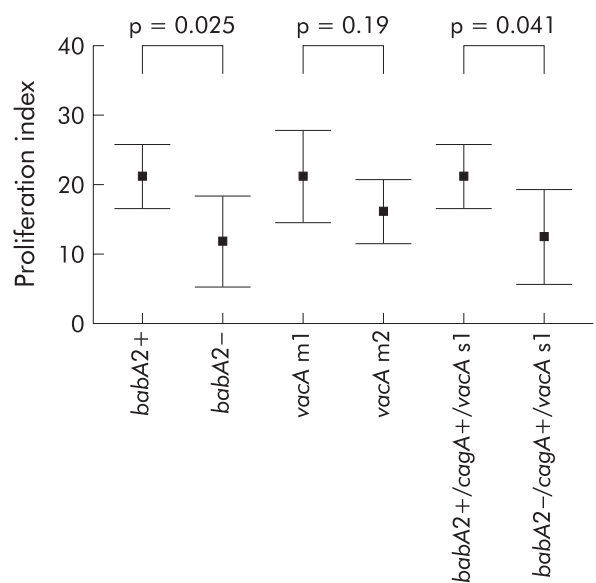

Figure 2 Proliferation index in different Helicobacter pylori genotypes. Results are plotted as mean and $95 \%$ confidence interval. The squares indicate the mean and the horizontal lines the upper and lower values of the $95 \%$ confidence interval. Significant differences were noted in the proliferation index between (a) babA2 ${ }^{+}$ and babA2- $(\mathrm{p}=0.025)$; and (b) babA2 $/ \mathrm{cag} A^{+} / \mathrm{vacA}$ s 1 and babA2 $/ \operatorname{cag} A^{+} / \operatorname{vacA}$ s1 ( $\left.p=0.041\right)$.

and between vacA $\mathrm{ml}$ and vacA $\mathrm{m} 2(0.62(0.54) v 0.65$ (0.49); mean difference $-0.02,95 \% \mathrm{CI}-0.26-0.2 \mathrm{l} ; \mathrm{p}=0.86)$ isolates.

\section{DISCUSSION}

In the present study, we have examined three genotypes (cagA, $v a c A$ and $b a b A 2$ ) that have been suggested to have higher pathogenic potential in $H$ pylori isolates from northern China. All $H$ pylori isolates were of the vacA sl genotype and $98 \%$ were $c a g A^{+}$, indicating that the cag $A^{+} / v a c A$ s 1 genotypes are highly prevalent in this population with a high background incidence of gastric cancer. Additionally, we found that approximately $80 \%$ of patients were infected with $b a b A 2^{+}$strains and $41.3 \%$ patients were harbouring vacA $\mathrm{ml}$ strains. Carriage of the $b a b A 2^{+}$strains was associated with more intense chronic inflammation (table 3), and presence of glandular AT and IM in the gastric antrum (table 4). This association with preneoplastic gastric lesions was also demonstrated in $H$ pylori isolates that were triple positive ( $b a b A 2^{+} / \mathrm{cagA}^{+} /$vacAsl) compared with $\mathrm{cagA}^{+} /$vacAsl strains that lacked $b a b A 2$. Recently, a similar association between gastric inflammation and $b a b A 2$ genotype was reported in a German study. ${ }^{21}$ The investigators reported that type I (cag $A^{+} / v a c A$ sl) $H$ pylori strains that were negative for $b a b A 2$ lacked the association with gastric inflammation and preneoplastic lesions. In contrast

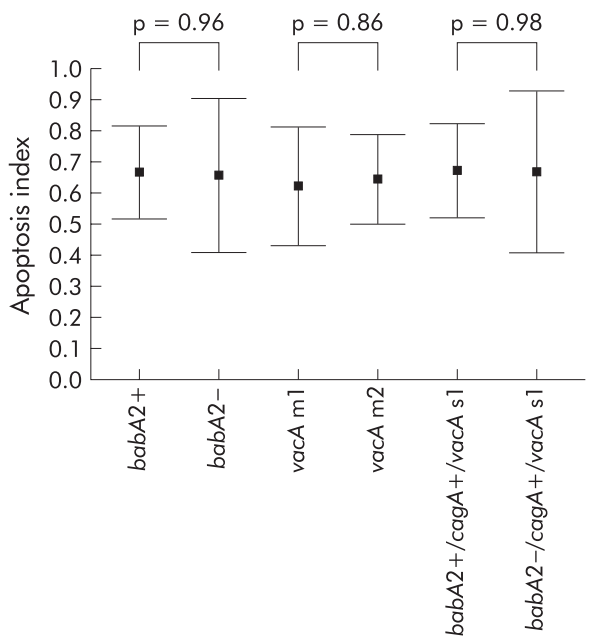

Figure 3 Apoptosis index in different Helicobacter pylori genotypes. Results are plotted as mean and 95\% confidence interval. There was no significant difference in apoptosis index between (a) babA2 $2^{+}$and $b a b A 2 ;$ (b) babA2 $/$ cag $A^{+} /$vacAsl and

babA2 $/ \operatorname{cag} A^{+} / \operatorname{vac} A s 1$; and (c) vacAm 1 and $\operatorname{vac} A m 2$.

with the German study that reported a $38 \%$ prevalence of the babA2 gene, babA2 was present in approximately $80 \%$ of our study population. In a recent Japanese study, the prevalence of the babA2 genotype was reported to be $85 \% .{ }^{22}$ The differential prevalence of babA2 $2^{+} \mathrm{H}$ pylori isolates in these three different studies appears to parallel the gastric cancer incidence of the countries. Countries with a high background incidence of gastric cancer such as Japan and China tend to have a higher frequency of babA2 $2^{+} H$ pylori. As attachment to gastric epithelial cells by $H$ pylori is mediated by BabA, it has been postulated that this attachment process precedes all other putative pathogenic processes..$^{21}$ Intuitively, adhesion to epithelial cells via BabA may facilitate the effective delivery of bacterial products such as the CagA protein into the host cells and the subsequent tyrosine phosphorylation process. ${ }^{23}$ None the less, babA2 is probably only one of the mediators for the attachment process and other unidentified factors are also likely to be involved. Otherwise, one might expect to find a wider difference in inflammation scores between infection by $b a b A 2^{+}$and $b a b A 2^{-}$isolates (table 3 ).

Age is one of the factors that may be associated with the presence of AT and IM in H pylori infected individuals. In our previous study, we showed that older subjects are more likely to demonstrate progression of metaplasia than younger 
subjects. ${ }^{14}$ However, even after adjustment for age, the frequencies of AT and IM were still significantly higher in individuals harbouring the $b a b A 2^{+}$strains or the triple positive $H$ pylori strain. In this study, we stratified patients into two groups, with 50 years as the dividing line, because this was the median age of our subjects. Moreover, in a previous decision analysis modelling study of $H$ pylori screening to prevent gastric cancer, the investigators suggested that screening at age $40-50$ years is considered to be reasonably cost effective. ${ }^{24}$ Therefore, it appears that most gastric changes related to chronic $H$ pylori infection had already developed at 50 years.

Disturbance in the balance between cellular proliferation and apoptosis may predispose to either cell loss with mucosal damage or cell accumulation and cancer development. ${ }^{25} 26$ Recent studies suggested that $H$ pylori infection increases gastric mucosal apoptosis in vivo. ${ }^{19}{ }^{27-30}$ However, the effect of $H$ pylori on gastric epithelial cell proliferation is conflicting. ${ }^{19} 2730-33$ One explanation for this discrepancy may be related to the presence of different bacterial genotypes. ${ }^{34} 35$ However, whether $H$ pylori adherence factors, such as BabA, affect cellular kinetics is unclear. Our findings demonstrated that subjects harbouring $H$ pylori babA2 ${ }^{+}$strains had significantly higher gastric proliferation rates than subjects with $b a b A 2^{-}$strains, which was unrelated to the degree of inflammation. More importantly, this increase in gastric cell proliferation was not accompanied by a parallel increase in apoptosis. Although the triple positive strains $\left(\mathrm{babA2}^{+} / \mathrm{cagA}^{+} /\right.$ vacAsl) had a similar increase in cell proliferation, the conventional type I ( $\mathrm{cagA}^{+} / \mathrm{vacA}$ sl) H pylori strains which were negative for $b a b A 2$ lacked such an association. In other words, in subjects infected with $H$ pylori babA2 ${ }^{+}$strains, there was dissociation between gastric epithelial cell proliferation and apoptosis, which may predispose to cancer development.

In conclusion, babA2 $H$ pylori isolates were present in approximately $80 \%$ of the study population from Yantai County where the incidence of gastric cancer is among the highest in China. The presence of babA2 $\mathrm{H}$ pylori strains alone, or in combination with $c a g A^{+} / v a c A s$, was associated with the presence of glandular AT and IM, and heightened gastric epithelial proliferation in the antrum. Carriage of babA2 $2^{+} H$ pylori strains and the associated changes in the gastric epithelium may partly explain the high background incidence of gastric cancer in the study population.

\section{ACKNOWLEDGEMENT}

The authors would like to express their gratitude to Jessica Ching, $\mathrm{MPH}$, and Albert Cheung, MSc, for statistical advice.

\section{Authors' affiliations}

J Yu, W K Leung, M Y Y Go, M C W Chan, F K L Chan, J J Y Sung, Department of Medicine and Therapeutics, Prince of Wales Hospital, Chinese University of Hong Kong, Shatin, Hong Kong K F To, Department of Anatomical and Cellular Pathology, Prince of Wales Hospital, Chinese University of Hong Kong, Shatin, Hong Kong E K W Ng, S C S Chung, Department of Surgery, Prince of Wales Hospital, Chinese University of Hong Kong, Shatin, Hong Kong T K W Ling, Department of Microbiology, Prince of Wales Hospital, Chinese University of Hong Kong, Shatin, Hong Kong

\section{REFERENCES}

1 Azuma T, Ito S, Sato F, et al. The role of the HLA-DQA 1 gene in resistance to atrophic gastritis and gastric adenocarcinoma induced by Helicobacter pylori infection. Cancer 1998:82:1013-18.

2 Correa P. Helicobacter pylori and gastric carcinogenesis. Am J Surg Pathol 1995;19(suppl 1):S37-43.

3 Correa P. Human gastric carcinogenesis: a multistep and multifactorial process-First American Cancer Society Award Lecture on Cancer Epidemiology and Prevention. Cancer Res 1992;52:6735-40.

4 Varis K, Taylor PR, Sipponen P, et al. Gastric cancer and premalignant lesions in atrophic gastritis: a controlled trial on the effect of supplementation with alpha-tocopherol and beta-carotene. The Helsinki Gastritis Study Group. Scand J Gastroenterol 1998;33:294-300.

5 Go MF, Kapur V, Graham DY, et al. Population genetic analysis of Helicobacter pylori by multilocus enzyme electrophoresis: extensive allelic diversity and recombinational population structure. J Bacterio 1996; 178:3934-8

6 Achtman M, Azuma T, Berg DE, et al. Recombination and clonal groupings within Helicobacter pylori from different geographical regions. Mol Microbiol 1999;32:459-70.

7 Covacci A. Censini S, Bugnoli M, et al. Molecular characterization of the $128-k D a$ immunodominant antigen of Helicobacter pylori associated with cytotoxicity and duodenal ulcer. Proc Natl Acad Sci USA 1993;90:5791-5

8 Parsonnet J, Friedman GD, Orentreich N, et al. Risk for gastric cancer in people with CagA positive or CagA negative Helicobacter pylori infection. Gut 1997:40:297-301.

9 Atherton JC, Cao P, Peek RM Jr, et al. Mosaicism in vacuolating cytotoxin alleles of Helicobacter pylori. Association of specific vacA types with cytotoxin production and peptic ulceration. J Biol Chem 1995;270: 17771-7.

10 Boren T, Falk P, Roth KA, et al. Attachment of Helicobacter pylori to human gastric epithelium mediated by blood group antigens. Science 1993;262: 1892-5

11 Boren T, Normark S, Falk P. Helicobacter pylori: molecular basis for host recognition and bacterial adherence. Trends Microbiol 1994;2:221-8.

12 Ilver D, Arnqvist A, Ogren J, et al. Helicobacter pylori adhesin binding fucosylated histo-blood group antigens revealed by retagging. Science 1998:279:373-7.

13 Gerhard $M$, Lehn N, Neumayer N, et al. Clinical relevance of the Helicobacter pylori gene for blood-group antigen-binding adhesin. Proc Natl Acad Sci USA 1999:96:12778-83.

14 Sung JJ, Lin SR, Ching JY, et al. Atrophy and intestinal metaplasia one year after cure of $\mathrm{H}$. pylori infection: a prospective, randomized study. Gastroenterology 2000;1 19:7-14

15 Siu LK, Leung WK, Cheng AF, et al. Evaluation of a selective transport medium for gastric biopsy specimens to be cultured for Helicobacter pylori. J Clin Microbiol 1998:36:3048-50.

16 Miehlke S, Yu J, Schuppler M, et al. Helicobacter pylori vacA, iceA, and cagA status and pattern of gastritis in patients with malignant and benign gastroduodenal disease. Am J Gastroenterol 2001;96:1008-13.

17 Yamaoka Y, Kodama T, Gutierrez O, et al. Relationship between Helicobacter pylori iceA, $\operatorname{cag} A$, and vacA status and clinical outcome: studies in four different countries. J Clin Microbiol 1999;37:2274-9.

18 Dixon MF, Genta RM, Yardley JH, et al. Classification and grading of gastritis. The updated Sydney System. International Workshop on the Histopathology of Gastritis, Houston 1994. Am J Surg Pathol 1996;20:1161-81

19 Leung WK, To KF, Chan FK, et al. Interaction of Helicobacter pylori eradication and non-steroidal anti-inflammatory drugs on gastric epithelial apoptosis and proliferation: implications on ulcerogenesis. Aliment Pharmacol Ther 2000;14:879-85.

20 Iftikhar SY, Steele RJ, Watson S, et al. Assessment of proliferation of squamous, Barrett's and gastric mucosa in patients with columnar lined Barrett's oesophagus. Gut 1992;33:733-7.

21 Prinz C, Schoniger M, Rad R, et al. Key importance of the Helicobacter pylori adherence factor blood group antigen binding adhesin during chronic gastric inflammation. Cancer Res 2001;61:1903-9.

22 Mizushima T, Sugiyama T, Komatsu Y, et al. Clinical relevance of the babA2 genotype of Helicobacter pylori in Japanese clinical isolates. $J$ Clin Microbiol 2001;39:2463-5.

23 Odenbreit S, Puls J, Sedlmaier B, et al. Translocation of Helicobacter pylori CagA into gastric epithelial cells by type IV secretion. Science 2000;287: 1497-500.

24 Parsonnet J, Harris RA, Hack HM, et al. Modelling cost-effectiveness of Helicobacter pylori screening to prevent gastric cancer: a mandate for clinical trial. Lancet 1996;348:150-4.

25 Moss SF. Cellular markers in the gastric precancerous process. Aliment Pharmacol Ther 1998;12(suppl 1):91-109.

26 Yoshimura T, Shimoyama T, Tanaka M, et al. Gastric mucosal inflammation and epithelial cell turnover are associated with gastric cancer in patients with Helicobacter pylori infection. J Clin Pathol 2000;53:532-6.

27 Moss SF, Calam J, Agarwal B, et al. Induction of gastric epithelial apoptosis by Helicobacter pylori. Gut 1996:38:498-501.

28 Mannick EE, Bravo LE, Zarama G, et al. Inducible nitric oxide synthase, nitrotyrosine, and apoptosis in Helicobacter pylori gastritis: effect of antibiotics and antioxidants. Cancer Res 1996;56:3238-43.

29 Jones NL, Shannon PT, Cutz E, et al. Increase in proliferation and apoptosis of gastric epithelial cells early in the natural history of Helicobacter pylori infection. Am J Pathol 1997:151:1695-703.

30 Peek RM Jr, Moss SF, Tham KT, et al. Helicobacter pylori cagA+ strains and dissociation of gastric epithelial cell proliferation from apoptosis. $J$ Natl Cancer Inst 1997;89:863-8.

31 Fraser AG, Sim R, Sankey EA, et al. Effect of eradication of Helicobacter pylori on gastric epithelial cell proliferation. Aliment Pharmacol Ther 1994;8: 167-73.

32 Bechi P, Balzi M, Becciolini A, et al. Helicobacter pylori and cell proliferation of the gastric mucosa: possible implications for gastric carcinogenesis. Am J Gastroenterol 1996;91:271-6.

33 Chow KW, Bank S, Ahn J, et al. Helicobacter pylori infection does not increase gastric antrum mucosal cell proliferation. Am J Gastroenterol 1995;90:64-6.

34 Zychlinsky A, Prevost MC, Sansonetti PJ. Shigella flexneri induces apoptosis in infected macrophages. Nature 1992;358:167-9.

35 Rokkas T, Ladas S, Liatsos C, et al. Relationship of Helicobacter pylor CagA status to gastric cell proliferation and apoptosis. Dig Dis Sci 1999:44:487-93. 